\title{
Sexual behaviour of people living with HIV attending a tertiary care government hospital in Kathmandu, Nepal: a cross sectional study
}

Mirak Raj Angdembe ${ }^{1 *}$, Shyam Prasad Lohani ${ }^{2}$, Deepak Kumar Karki ${ }^{3}$, Kreepa Bhattarai ${ }^{4}$ and Niraj Shrestha ${ }^{5}$

\begin{abstract}
Background: Clinical improvements that follow antiretroviral therapy (ART) may lead to increase or resumption of high risk activities that could unintentionally result in HIV transmission. The objective was to investigate whether treatment status is a significant predictor of sexual risk behaviour (unprotected sex).

Methods: A cross sectional study was conducted among 160 people living with HIV (PLHIV) (89 ART experienced and 71 ART naïve) attending Sukraraj Tropical and Infectious Disease Hospital in Kathmandu, Nepal. A structured questionnaire was used for data collection. Logistic regression with stepwise modeling was used to obtain adjusted odds ratios (OR) with $95 \% \mathrm{Cl}$.

Results: In this study, $92 \%$ of sexually active respondents reported sex with a regular partner. ART experienced PLHIV were significantly more likely to report consistent condom use with their regular partners compared to ART naïve PLHIV (83 vs. $53 \% ; P=0.006$ ) during the past six months. In multivariate analysis, sex (OR $=4.59,95 \% \mathrm{Cl}: 1.15-18.39$ ), treatment status $(\mathrm{OR}=4.76,95 \% \mathrm{Cl}: 1.29-17.52)$ and alcohol consumption during last sex with regular partners $(\mathrm{OR}=14.75,95 \% \mathrm{Cl}: 2.75-79.29)$ were significantly associated with unprotected sex.

Conclusion: ART naïve PLHIV were five times more likely to exhibit sexual risk behaviour (have unprotected sex) than ART experienced PLHIV. Thus the study provided no evidence to suggest that ART experienced PLHIV exhibit greater sexual risk behaviour compared to ART naïve PLHIV. Prevention programmes need to emphasize on counselling to PLHIV and their regular partners with focused interventions such as couple counselling and education programmes.
\end{abstract}

Keywords: Antiretroviral therapy, Sexual behaviour, HIV, AIDS, Nepal

\section{Background}

The development of antiretroviral therapy (ART) has led to reduction in mortality and morbidity rates among people living with HIV (PLHIV) [1, 2]. An early initiation of ART will lead to near normal quality of life and lifespan [3-5]. ART reduces the concentration of the virus in plasma which is a primary determinant of the risk of transmission [6]. Reduction in risk of transmission to sexual partners among those initiating ART will depend

\footnotetext{
*Correspondence: mirak.angdembe@gmail.com

1 Department of Public Health, Central Institute of Science

and Technology, Pokhara University, Kathmandu, Nepal

Full list of author information is available at the end of the article
}

upon viral load in plasma and genital tract $[1,7]$. Even with the infected partner on effective ART and undetectable viral loads, transmission of HIV although rare has been documented [8-10]. Thus, risk is substantially reduced [11-15] but not completely eliminated.

Clinical improvements that follow ART may lead to increase or resumption of high risk activities that could unintentionally result in HIV transmission [16]. Optimism related to the success of ART in slowing disease progression, reducing viral load, and improving health status [17] might be crucial factors determining sexual risk behaviours. Since highly active ART (HAART) became available, there has been an increase in sexual 
risk behaviour among the PLHIV [18-22]. Beliefs about reduced risk for HIV transmission with ART may also influence the behaviour [23]. In contrast, a meta-analysis did not find an increase in sexual risk behaviour following ART. However, it did report a higher likelihood of unprotected sex in individuals who believed that therapy prevented transmission or who were less concerned about transmission given the availability of ART [24]. Additionally, use of ART was not associated with increased sexual risk behaviour in PLHIV undergoing ART [25, 26]; homosexual men receiving ART [27]; HIV infected injecting drug users [16]. Some studies suggest a decrease or lower sexual risk behaviour following ART [22, 28-30].

With increased sexual risk behaviour there is also the possibility of transmission of drug resistant HIV strains. Between 7 and $17 \%$ of newly infected people in high income countries carry at least one major drug resistance mutation [31,32]. On the other hand, middle and low income countries are estimated to have a lower prevalence of transmitted drug resistance at around 7 \% [32]. This situation however is likely to change with increased availability of ART. Evidence from East and Southern Africa already show a rapid increase in transmitted drug resistance following ART rollout [33]. In addition to drug resistance, there is also the risk of superinfection, which is defined as an infection with a second strain following the initial infection and immune response [34]. With an estimated incidence of 0-7.7\% per year, superinfections have adverse effects on clinical outcomes and might affect ART scale up plans [35]. Thus even with the possibility of ART for prevention, the importance of safe sexual practice cannot be undermined.

In Nepal, ART was initiated in 2004 by Sukraraj Tropical and Infectious Disease Hospital, a tertiary care hospital run by Government of Nepal in Teku, Kathmandu [36]. By the end of 2014, the government was providing ART free of cost to 10,407 PLHIV from 53 ART centres across the country [36]. According to national guidelines, ART is initiated when the CD4 cell count is $\leq 500$ cells/ $\mathrm{mm}^{3}$ with priority to those with WHO clinical stage 3 or 4 disease. It is also recommended to initiate ART in people with active tuberculosis (TB) disease and hepatitis B virus co-infection with severe liver disease, all pregnant and breastfeeding women with HIV, and all individuals with HIV in serodiscordant relationships, regardless of CD4 cell count [37]. Those who do not fulfil these criteria are considered Pre ART (ART naïve) individuals who are regularly monitored for $\mathrm{CD} 4$ cell count and treated for opportunistic infections (OI) when necessary.

With increase in treatment coverage, greater number of people are expected to survive in Nepal, indicating an increase in prevalence of HIV infection among treated populations. In Nepal, it is estimated that more than $85 \%$ of the total new HIV infections are the result of sexual transmission [38]. A small change in sexual risk behaviour in such population could have a large impact on the course of the epidemic. Studies from South Africa and Uganda have developed models which suggest that increases in sexual risk behaviour by those initiating ART could reduce expected declines in HIV incidence [39, 40]. It has been estimated that the probability for HIV epidemic eradication through widespread ART use is $85 \%$ if sexual risk behaviour decreases [41]. If levels of risky sex remain stable, that probability decreases to $50 \%$, and decreases further in the presence of increased sexual risk behaviours [41].

Thus this study was conducted to learn more about the impact of ART on sexual risk behaviour. The objective was to investigate whether treatment status (ART experienced vs. ART naïve) is a significant predictor of sexual risk behaviour among PLHIV attending a tertiary care government hospital in Kathmandu, Nepal.

\section{Methods}

This was a cross sectional study where sexual behaviour of PLHIV was investigated. We collected data from the ART clinic of Sukraraj Tropical and Infectious Disease Hospital, Teku, Kathmandu, one of the tertiary care hospitals in the capital city of Nepal, during July-August 2010. This is the largest ART centre in the country where PLHIV are referred from various districts.

A total of 160 PLHIV (89 ART experienced and 71 ART naïve) were conveniently enrolled for structured interviews. It was assumed that the PLHIV visit the center in a natural random order. Every PLHIV who visited the center during clinic hours was considered for the study with enrollment based on certain criteria. The study included only those PLHIV who were enrolled in HIV care for at least six months since HIV was diagnosed, who were 18 years of age or older and had not initiated ART (ART naïve PLHIV) or ART experienced for at least six months. PLHIV who were hearing and speech impaired, seriously ill or admitted to hospital and those who could not give informed consent were not enrolled in the study. It was presumed that pregnancy and TB infection would affect the sexual behaviour of PLHIV. Thus they were also excluded.

PLHIV's medical records maintained in the ART clinic were reviewed to record the latest CD4 cell count in the past six months and date when HIV was diagnosed. Measure of CD4 cell count could not be obtained for all respondents because medical records were not updated. Names and other identifying information were not obtained. Interviews were conducted using a structured questionnaire to collect behavioral information. The 
questionnaire (Additional file 1) was adapted from standardized questions used in integrated biological and behavioral surveillance (IBBS) surveys in Nepal with established validity and reliability [42]. It was then discussed among experts for further validation. The questionnaire was pretested among $10 \%$ (16) of the anticipated sample size at the study site itself. During pre-testing, respondents hesitated to answer the question on whether they had penileanal sex with men or women. The concept was detested and considered unnatural. Thus the definition of sex was limited to penile vaginal insertive sexual events and the study inquired only heterosexual behavior.

The key themes of analysis for sexual risk behaviour were type of partners (regular, commercial and casual partners), knowledge of partner's HIV status, disclosure of own HIV status to partners, alcohol consumption during last sex with partners, condom use during last sex and consistent condom use with partners. The recall reference period was six months. Sex was defined as penile vaginal insertive sexual events during the past six months. A person reporting to be involved in sex with one or more sexual partners during the past six months was defined as sexually active. A commercial partner was defined as a partner to whom the respondent paid in cash or kind in exchange for sex. A regular partner was defined as a spouse or someone with whom the respondent had a stable relationship such as boyfriend/girlfriend or live-in sexual partner who was never paid for sex. A casual partner was defined as a sexual partner with whom the respondent had sex only once or rarely, was not living with or married to and never paid (in cash or kind) for sex. Unprotected sex was defined as no condom use at last sex or inconsistent (sometimes or never) condom use during sex with regular partners during the past six months.

The process of data management started at the study site with review of the completed questionnaire for possible errors. Data were entered in SPSS (ver.17) and analyzed using SPSS (ver.17) and Stata (ver.12). Before analysis, the data were checked and rechecked for missing values by analyzing frequencies. Fisher's exact test was used to determine statistically significant differences for categorical variables. Logistic regression analysis was performed to examine the effects of independent variables on sexual behaviour with regular partners. The outcome variable sexual behaviour was coded as $0=$ protected sex and $1=$ unprotected sex. Initially, independent variables were included in the model one at a time to examine their univariate relationship with sexual behaviour. This was followed by the development of a multivariate model. Using an empty model to begin with, variables were fitted one at a time (stepwise modeling). At each stage, the least significant variable was excluded until the model contained only statistically significant factors. A $P$-value of $<0.05$ was considered to be statistically significant.

The study protocol was reviewed and approved by the Ethical Review Board of the Faculty of Health Sciences, Nobel College, Pokhara University and Sukraraj Tropical and Infectious Disease Hospital, Teku. The respondents were given complete and clear information about the study being conducted enabling them to make an informed decision whether or not to participate in the study. The informed consent was obtained verbally from all respondents.

\section{Results}

The mean age of the respondents was 34.5 years ( $\mathrm{SD}= \pm 6.62$ ). Other background characteristics of respondents are presented in Table 1 . Majority of the respondents were Hindus (70\%), married or living with a partner (63\%) currently employed (80\%), having secondary level education (42\%) and earning monthly income in the range of Nepalese rupees (NRs.) 500010,000 (53 \%) (1US Dollar = NRs. 105, as of September 2015 [43]). Among those employed, most were engaged in agriculture (23\%) followed by business (19 \%) (not shown in table). The mean time since HIV diagnosed was 41 months ( $\mathrm{SD}= \pm 3.2)$ and the mean CD4 cell count in the past six months $(\mathrm{n}=146)$ was 242 cells $/ \mathrm{mm}^{3}$ $(\mathrm{SD}= \pm 13.1)$ (Not shown in table).

Fifty-two percent $(83 / 160)$ of respondents reported having had sexual intercourse during the past six months (ART experienced $=51 \%$ and ART naïve $=53 \%$ ). Ninety-two percent (76/83) of sexually active respondents reported sex with a regular partner (ART experienced $=93 \%$ and ART naïve $=89 \%$ ) (Table 2). A greater number of ART experienced PLHIV reported consistent condom use with their regular partner compared to ART naïve PLHIV (83 vs. $53 \% ; P=0.006$ ). ART experienced PLHIV reported greater condom use at last sex with their regular partner than ART naïve PLHIV (84 vs. $66 \%)$ but the difference was not statistically significant. Nearly $83 \%$ of ART experienced and $71 \%$ of ART naïve PLHIV knew their regular partner's HIV status. Likewise, $88 \%$ of ART experienced and $85 \%$ of ART naïve PLHIV disclosed their own HIV status to their regular partner. A majority of the ART experienced ( $83 \%$ ) and ART naive (82 \%) PLHIV did not consume alcohol during last sex with regular partner. Compared to ART experienced PLHIV a greater number of ART naïve PLHIV believed that ART can prevent the transmission of HIV (44 vs. $61 \% ; P=0.040)$.

Regarding the decision to use/not use condom during last sex with regular partners, a majority (61\%) of the males reported that they themselves took the decision to 
Table 1 Socio demographic characteristics of the respondents

\begin{tabular}{lc}
\hline Variables (N= 160) & $\mathbf{n}(\%)$ \\
\hline Sex, female & $58(36.3)$ \\
Current residence, inside Kathmandu valley & $81(50.6)$ \\
Religion & \\
Hindu & $107(66.9)$ \\
Buddhist & $21(13.1)$ \\
Christian & $26(16.2)$ \\
Islam & $6(3.8)$ \\
Ethnicity & \\
Brahmin/Chhetri & $73(45.6)$ \\
Janajati & $68(42.5)$ \\
Others & $19(11.9)$ \\
Marital status & \\
Married or living with a partner & $101(63.1)$ \\
Unmarried/single & $20(12.5)$ \\
Divorced/separated & $12(7.5)$ \\
Widow/widower & $27(16.9)$ \\
Education status & \\
No education & $48(30.0)$ \\
Primary (1-5) & $26(16.2)$ \\
Secondary (6-10) & $67(41.9)$ \\
Higher & $19(11.9)$ \\
Unemployed & $32(20.0)$ \\
Monthly income in Nepali rupees ${ }^{\mathrm{b}}(\mathrm{n}=98)$ & \\
5000-10,000 & $28(28.6)$ \\
$>10000$ & $52(53.1)$ \\
\hline Janajta & $18(18.3)$ \\
\hline
\end{tabular}

a Janajati are considered as indigenous population groups who are specifically resided in local areas in various parts of country; whereas Brahmins/Chhetries are considered as upper class ethnic groups and have relatively more access to resources, power and identity [54]

b 1 US\$ $=105$ Nepali rupees

use/not use condom. However in the case of females, a majority $(80 \%)$ reported that their male partner or both took the decision to use/not use condom and only $20 \%$ of them reported that they themselves took the decision (not shown in table). This difference was significant $(P=0.004)$.

In univariate analysis, two variables were significantly associated with unprotected sex (Table 3). However in the final logistic regression model, three variables were significantly associated with unprotected sex: sex $(\mathrm{OR}=4.59,95 \% \mathrm{CI}: 1.15-18.39)$, treatment status $(\mathrm{OR}=4.76,95 \%$ CI: 1.29-17.52) and alcohol consumption during last sex with regular partners $(\mathrm{OR}=14.75$, 95 \% CI: 2.75-79.29). Sex was not significant in univariate analyses but was found to be significant in multivariate analysis.

\section{Discussion}

Rapid development in the field of ART has led to reduction in morbidity and mortality among PLHIV. However, there is a growing concern over sexual risk behaviour of PLHIV on ART. The changes in sexual risk behaviour of PLHIV with the initiation of ART might have important implications on the way counseling may be designed and implemented. An increase in sexual risk behaviour with therapy will be a matter of great concern from a prevention of transmission perspective. If not intervened, it may further fuel the epidemic.

In this study, only around half of the respondents reported to be sexually active in the past six months. It is possible that lower sexual activity may be a result of symptomatic disease or a result of adverse effects of ART [23]. The psychological trauma resulting from a positive diagnosis might also reduce sexual desire. A majority of the respondents in both groups (ART experienced and ART naïve) had sex only with their regular partners in the past six months. Those who had other types of partners always used condoms during sex except for one male ART naïve PLHIV who never used condom with his casual partner. This meant that sexual risk behaviour was mostly dependent upon the respondents' condom use with their regular partners. This is similar to other studies where most reported sex was with regular partners [17, 30, 44]. In India, $96 \%$ of those who were sexually active in the past six months reported sex with a regular partner [17]. However, we should consider the influence of both recall and social desirability bias on responses related to sexual behaviour when interpreting these results.

In regular partner relationship, non-disclosure of self's HIV status, lack of knowledge of partner's HIV status in combination with unprotected sex lays out favourable circumstances for transmission of HIV to serodiscordant partners. Furthermore unprotected sex with regular partner also carries the risk of unwanted pregnancy and the transmission of HIV virus to the child. Nearly a fifth $(20 \%)$ of the respondents who had sex with regular partners were in a discordant relationship with an HIV negative partner but a majority of them (93\%) had protected sex. Likewise, $58 \%$ were in a concordant relationship with an HIV positive partner but a relatively lower percentage $(66 \%)$ reported protected sex. Unprotected sex with HIV positive partners carries the risk of becoming infected with resistant viral strains or reinfection with novel strains [30].

With regular partners, ART experienced PLHIV were more likely to have protected sex compared to ART naïve PLHIV, which was similar to other studies conducted in a developing country setting $[17,25,30]$. Thus, the study provides no evidence to suggest that sexual risk behaviour may actually increase with initiation of ART in this 
Table 2 Sexual behaviour in the previous six months and belief towards ART

\begin{tabular}{|c|c|c|c|}
\hline Variables & $\begin{array}{l}\text { ART experienced } \\
\mathrm{n}(\%)\end{array}$ & $\begin{array}{l}\text { ART Naïve } \\
\text { n (\%) }\end{array}$ & $P^{a}$-value \\
\hline \multicolumn{4}{|l|}{ Sexually active in the past six months } \\
\hline Yes $(n=83)$ & $45(50.6)$ & $38(53.5)$ & \multirow[t]{2}{*}{0.752} \\
\hline No & $44(49.4)$ & $33(46.5)$ & \\
\hline \multicolumn{4}{|l|}{ Sex with $(n=83)$} \\
\hline Regular partner & $42(93.3)$ & $34(89.5)$ & \multirow[t]{2}{*}{0.697} \\
\hline Commercial and casual partners & $3(6.7)$ & $4(10.5)$ & \\
\hline \multicolumn{4}{|l|}{ Condom use with regular partners } \\
\hline Consistent (always) & $35(83.3)$ & $18(52.9)$ & \multirow[t]{2}{*}{0.006} \\
\hline Inconsistent (sometimes and never) & $7(16.7)$ & $16(47.1)$ & \\
\hline \multicolumn{4}{|c|}{ Condom use at last sex with regular partner } \\
\hline Yes & $38(84.4)$ & $25(65.8)$ & \multirow[t]{2}{*}{0.071} \\
\hline No & 7 (15.6) & $13(34.2)$ & \\
\hline \multicolumn{4}{|l|}{ Knowledge of regular partner's HIV status } \\
\hline Known & $35(83.3)$ & $24(70.6)$ & \multirow[t]{2}{*}{0.269} \\
\hline Not known & $7(16.7)$ & $10(29.4)$ & \\
\hline \multicolumn{4}{|l|}{ Disclosure of HIV status to regular partner } \\
\hline Yes & $37(88.1)$ & $29(85.3)$ & \multirow[t]{2}{*}{0.745} \\
\hline No & $5(11.9)$ & $5(14.7)$ & \\
\hline \multicolumn{4}{|c|}{ Alcohol consumption during last sex with regular partner } \\
\hline Yes & $7(16.7)$ & $6(17.6)$ & \multirow[t]{2}{*}{1.000} \\
\hline No & $35(83.3)$ & $28(82.4)$ & \\
\hline \multicolumn{4}{|l|}{ Can ART prevent the transmission of HIV } \\
\hline Yes/don't know & $39(43.8)$ & $43(60.6)$ & \multirow[t]{2}{*}{0.040} \\
\hline No & $50(56.2)$ & $28(39.4)$ & \\
\hline \multicolumn{4}{|c|}{ With availability of ART would it make a difference if HIV transmits from you to others } \\
\hline Yes & $78(87.6)$ & $56(78.9)$ & \multirow[t]{2}{*}{0.195} \\
\hline No/don't know & $11(12.4)$ & $15(21.1)$ & \\
\hline
\end{tabular}

a Fisher's exact test

context $[23,25,26,28-30]$. Belief about the reduced severity and threat of the disease due to the availability of HAART as well as those about HAART related HIV transmission might have contributed to increased sexual risk behaviour [24] particularly among ART naïve PLHIV compared to ART experienced PLHIV. On the other hand, lower risk behaviour among ART experienced may be explained when taking into account their larger mean time since HIV diagnosis (43 months) compared to ART naïve PLHIV (29 months). This means a longer time had elapsed since getting tested and diagnosed with greater chances of having advanced HIV disease as well. Consequently they may perceive the seriousness of their illness differently and should have had several contacts with health workers including counsellors who conveyed prevention and protection messages during the course of treatment. This may have contributed to lower sexual risk behaviour. In addition, similar to a study in India, the belief that condoms are needed for ART to be effective might have facilitated consistent condom use with regular partners [45] among ART experienced PLHIV. Among married couples, the desire to have children might also be a predictor of unprotected sex with regular partners [46] but it was not investigated in this study. In order to get a clear understanding of the underlying reasons for unprotected sex, it might be necessary to investigate individual motives through a qualitative inquiry.

Females were more likely to have unprotected sex compared to males. The decision to use/not use condom was taken mostly by the males. Females seem to have very little say when it comes to deciding on condom use. This might have contributed to this finding. A study from Asia found that wealthier and highly educated married women were more likely to report that they can refuse sexual intercourse and ask their husbands to use a condom [47]. Additionally the study had also found that women's overall involvement in making family decisions empowers them to negotiate safer sex [47]. 
Table 3 Predictors of unprotected sex with regular partners

\begin{tabular}{|c|c|c|c|c|c|c|}
\hline Variables & $\begin{array}{l}\text { Unprotected } \\
\mathrm{n}(\%)\end{array}$ & $\begin{array}{l}\text { Protected } \\
\text { n (\%) }\end{array}$ & $\begin{array}{l}\text { Univariate OR } \\
(95 \% \mathrm{Cl})\end{array}$ & $P$-value & $\begin{array}{l}\text { Multivariate OR } \\
(95 \% \mathrm{Cl})\end{array}$ & $P$-value \\
\hline \multicolumn{7}{|l|}{ Sex } \\
\hline Female & $9(45.0)$ & $11(55.0)$ & $2.46(0.84-7.15)$ & 0.100 & $4.59(1.15-18.39)$ & 0.031 \\
\hline Male & $14(25.0)$ & $42(75.0)$ & & & & \\
\hline \multicolumn{7}{|l|}{ Marital status } \\
\hline Not living with a partner & $1(50.0)$ & $1(50.0)$ & $2.36(0.14-39.5)$ & 0.549 & & \\
\hline Living with a partner & $22(30.0)$ & $52(70.0)$ & & & & \\
\hline \multicolumn{7}{|l|}{ Education level $^{\mathrm{b}}$} \\
\hline Formal education & $18(30.5)$ & $41(69.5)$ & $1.05(0.32-3.43)$ & 0.931 & & \\
\hline No formal education & $5(29.4)$ & $12(70.6)$ & & & & \\
\hline \multicolumn{7}{|l|}{ Occupation } \\
\hline Unemployed & $6(46.2)$ & $7(53.8)$ & $2.32(0.68-7.89)$ & 0.178 & & \\
\hline Employed & $17(26.9)$ & $46(73.1)$ & & & & \\
\hline \multicolumn{7}{|l|}{ Treatment status } \\
\hline ART naïve & $16(47.1)$ & $18(52.9)$ & $4.44(1.55-12.76)$ & 0.006 & $4.76(1.29-17.52)$ & 0.019 \\
\hline ART experienced & $7(16.7)$ & $35(83.3)$ & & & & \\
\hline \multicolumn{7}{|l|}{ Partner's HIV status } \\
\hline Not known & $7(41.2)$ & $10(58.8)$ & $1.35(0.43-4.27)$ & 0.606 & & \\
\hline HIV negative & $1(6.7)$ & $14(93.3)$ & $0.14(0.02-1.15)$ & 0.068 & & \\
\hline HIV positive & $15(34.1)$ & $29(65.9)$ & & & & \\
\hline \multicolumn{7}{|l|}{ Disclosure of own HIV status } \\
\hline No & $5(50.0)$ & $5(50.0)$ & $2.67(0.69-10.31)$ & 0.155 & & \\
\hline Yes & $18(27.3)$ & $48(72.7)$ & & & & \\
\hline \multicolumn{7}{|c|}{ Alcohol consumption during last sex } \\
\hline Yes & $9(69.2)$ & $4(30.8)$ & $7.88(2.11-29.45)$ & 0.002 & $14.75(2.75-79.29)$ & 0.002 \\
\hline No & $14(22.2)$ & $49(77.8)$ & & & & \\
\hline \multicolumn{7}{|c|}{ Time since HIV was diagnosed ${ }^{\mathrm{a}}$} \\
\hline$\leq 24$ months & $14(40.0)$ & $21(60.0)$ & $2.37(0.87-6.46)$ & 0.091 & & \\
\hline$>24$ months & $9(21.9)$ & $32(78.1)$ & & & & \\
\hline \multicolumn{7}{|l|}{ CD4 Cell count $\left(\text { cells } / \mathrm{mm}^{3}\right)^{\mathrm{a}}$} \\
\hline$\leq 224$ & $12(37.5)$ & $20(62.5)$ & $2.18(0.75-6.28)$ & 0.151 & & \\
\hline$>224$ & $8(21.6)$ & $29(78.4)$ & & & & \\
\hline \multicolumn{7}{|c|}{ Can ART prevent the transmission of HIV } \\
\hline Yes/don't know & $14(35.0)$ & $26(65.0)$ & $1.61(0.60-4.37)$ & 0.345 & & \\
\hline No & $9(25.0)$ & $27(75.0)$ & & & & \\
\hline \multicolumn{7}{|c|}{ With availability of ART would it make a difference if HIV transmits from you to others } \\
\hline Yes & $18(27.7)$ & $47(72.3)$ & $0.46(0.12-1.70)$ & 0.243 & & \\
\hline No/don't know & $5(45.4)$ & $6(54.6)$ & & & & \\
\hline
\end{tabular}

${ }^{a}$ Dichotomization based on sample median

b Formal education includes primary (grade 1-5), secondary (grade 6-10), higher secondary/high school (grade 11-12), under graduate and post graduate

Alcohol consumption during last sex with regular partners was one of the significant predictors of unprotected sex. The use of alcohol may decrease the ability to make rational judgements and provoke risk behaviours as unprotected sex. Studies conducted in different populations and high risk sub-groups have attempted to examine the relationship where a number of them report an association between risk behaviour and alcohol consumption [45, 46, 48-52]. On the contrary, a metaanalysis to assess the relationship of alcohol use and condom use did not find an association [53].

Similar to the limitations of other previous studies, [44] this current cross-sectional study could not derive causal inferences. Further, the study defined sex as penile vaginal insertive sexual events which meant that other risky sexual behaviour including penile-anal sex between 
men and between men and women were not accounted for. In the multivariate analysis, the reduction in sample size may have resulted in wider confidence intervals. Thus, the conclusions may be tentative, especially with regards to the non-significant findings. The fact that sex of the person was statistically significant only in the multivariate analysis, once ART status was controlled for may indicate an interaction effect, but this could not be tested with the small sample size. These limitations should be taken into consideration when interpreting the results of this study. Also, since sexual behaviour was self-reported it may have been underestimated [28, 30, 44]. Furthermore, it is also important to note the possible influence of social desirability on study results.

\section{Conclusions}

Treatment status was found to be a significant predictor of sexual risk behaviour with regular partners. ART naïve PLHIV were five times more likely to exhibit sexual risk behaviour (have unprotected sex) with regular partners than ART experienced PLHIV. Regular partners such as spouses are an important group as far as prevention of transmission is concerned as they are the most likely partners.

In addition to having targeted prevention programmes for high risk sub-populations, the study highlights the need to emphasize on counselling to PLHIV and their regular partners. Focused interventions such as couple counselling and education programmes are required to be built into the total HIV care and treatment programme. Practicing safer sex with regular sexual partners and refraining from alcohol use during sex should be the critical messages. Additionally, programmes should focus on empowering women to make decisions regarding condom use during sex. In the future, a longitudinal study with adequate sample size can provide causal inferences regarding the impact of ART on sexual behaviours.

\section{Additional file}

Additional file 1. English version of the questionnaire.

\section{Authors' contributions}

MRA designed the study, performed data collection and statistical analysis, drafted the manuscript and made critical revisions. SPL participated in the design of the study, supervised the study and contributed to drafting the manuscript. DKK participated in the design of the study and drafting of the manuscript. KB and NS participated in data collection and helped in preparation of the manuscript. All authors read and approved the final manuscript.

\footnotetext{
Author details

${ }^{1}$ Department of Public Health, Central Institute of Science and Technology, Pokhara University, Kathmandu, Nepal. ${ }^{2}$ Centre for Health Research and International Relations, Nobel College, Pokhara University, Kathmandu, Nepal. ${ }^{3}$ National Centre for AIDS and STD Control, Kathmandu, Nepal. ${ }^{4}$ Braun School of Public Health and Community Medicine, Hebrew University, Jerusalem,
}

Israel. ${ }^{5}$ Melbourne School of Population and Global Health, The University of Melbourne, Melbourne, Australia.

\section{Acknowledgements}

First, we would like to thank Nathan Martin Reynolds, Braun School of Public Health and Community Medicine, Hebrew University, Jerusalem, Israel for reviewing the manuscript for language corrections. Last but not the least we are grateful to all PLHIV who contributed with voluntary participation in the study.

\section{Competing interests}

The authors declare that they have no competing interests.

Received: 28 February 2012 Accepted: 5 October 2015

Published online: 02 November 2015

\section{References}

1. Cohen MS, Gay C, Kashuba AD, Blower S, Paxton L. Narrative review: antiretroviral therapy to prevent the sexual transmission of HIV-1. Ann Intern Med. 2007;146:591-601.

2. Ray M, Logan R, Sterne JA, Hernandez-Diaz S, Robins JM, Sabin C, Bansi $L$, van Sighem A, de Wolf F, Costagliola D, et al. The effect of combined antiretroviral therapy on the overall mortality of HIV-infected individuals. AIDS. 2010;24:123-37.

3. Nakagawa F, Lodwick RK, Smith CJ, Smith R, Cambiano V, Lundgren JD, Delpech V, Phillips AN. Projected life expectancy of people with HIV according to timing of diagnosis. AIDS. 2012;26:335-43.

4. Johnson LF, Mossong J, Dorrington RE, Schomaker M, Hoffmann CJ, Keiser O, Fox MP, Wood R, Prozesky H, Giddy J, et al. Life expectancies of South African adults starting antiretroviral treatment: collaborative analysis of cohort studies. PLoS Med. 2013;10:e1001418.

5. Nakagawa F, May M, Phillips A. Life expectancy living with HIV: recent estimates and future implications. Curr Opin Infect Dis. 2013;26:17-25.

6. Quinn TC, Wawer MJ, Sewankambo N, Serwadda D, Li C, WabwireMangen F, Meehan MO, Lutalo T, Gray RH. Viral load and heterosexual transmission of human immunodeficiency virus type 1. Rakai Project Study Group. N Engl J Med. 2000;342:921-9.

7. Wood E, Kerr T, Montaner JS. HIV treatment, injection drug use, and illicit drug policies. Lancet. 2007;370:8-10.

8. Stürmer M, Doerr HW, Berger A, Gute P. Is transmission of HIV-1 in nonviraemicserodiscordant couples possible? Antivir Ther. 2008;13:729-32.

9. Attia S, Egger M, Muller M, Zwahlen M, Low N. Sexual transmission of HIV according to viral load and antiretroviral therapy: systematic review and meta-analysis. AIDS. 2009;23:1397-404.

10. Lu W, Zeng G, Luo J, Duo S, Xing G, Guo-Wei D, Jian-Ping Z, Wen-Sheng H, Ning W. HIV transmission risk among serodiscordant couples: a retrospective study of former plasma donors in Henan, China. J Acquir Immune Defic Syndr. 2010;55:232-8.

11. Temoshok LR, Wald RL. Integrating multidimensional HIV prevention programs into healthcare settings. Psychosom Med. 2008;70:612-9.

12. Porco TC, Martin JN, Page-Shafer KA, Cheng A, Charlebois E, Grant RM, Osmond $\mathrm{DH}$. Decline in HIV infectivity following the introduction of highly active antiretroviral therapy. AIDS. 2004;18:81-8.

13. Loutfy MR, Wu W, Letchumanan M, Bondy L, Antoniou T, Margolese S, Zhang Y, Rueda S, McGee F, Peck R, et al. Systematic review of HIV transmission between heterosexual serodiscordant couples where the HIV-positive partner is fully suppressed on antiretroviral therapy. PLoS One. 2013;8:e55747

14. Baggaley RF, White RG, Hollingsworth TD, Boily MC. Heterosexual HIV-1 infectiousness and antiretroviral use: systematic review of prospective studies of discordant couples. Epidemiology. 2013;24:110-21.

15. Anglemyer A, Rutherford GW, Horvath T, Baggaley RC, Egger M, Siegfried N. Antiretroviral therapy for prevention of HIV transmission in HIV-discordant couples. Cochrane Database Syst Rev. 2013;4:CD009153.

16. Bouhnik AD, Moatti JP, Vlahov D, Gallais H, Dellamonica P, Obadia Y. Highly active antiretroviral treatment does not increase sexual risk behaviour among French HIV infected injecting drug users. J Epidemiol Community Health. 2002;56:349-53. 
17. Sarna A, Gupta I, Pujari S, Sengar AK, Garg R, Weiss E. Examining adherence and sexual behavior among patients on antiretroviral therapy in India. Horizons final report. Washington, D.C.: Population Council; 2006.

18. Chen SY, Gibson S, Katz MH, Klausner JD, Dilley JW, Schwarcz SK, Kellogg TA, McFarland W. Continuing increases in sexual risk behaviour and sexually transmitted diseases among men who have sex with men: San Francisco, Calif, 1999-2001, USA (letter). Am J Public Health. 2002;92:1387-8.

19. Dukers NH, Goudsmit J, de Wit JB, Prins M, Weverling GJ, Coutinho RA. Sexual risk behaviour relates to the virological and immunological improvements during highly active antiretroviral therapy in HIV-1 infection. AIDS. 2001;15:369-78.

20. Katz MH, Schwarcz SK, Kellogg TA, Klausner JD, Dilley JW, Gibson S, McFarland W. Impact of highly active antiretroviral treatment on HIV seroincidence among men who have sex with men: San Francisco. Am J Public Health. 2002;92:388-94.

21. Scheer S, Chu PL, Klausner JD, Katz MH, Schwarcz SK. Effect of highly active antiretroviral therapy on diagnoses of sexually transmitted diseases in people with AIDS. Lancet. 2001;357:432-5.

22. Wilson TE, Gore ME, Greenblatt R, Cohen MS, Minkoff H, Silver S, Robison E, Levine A, Gange SJ. Changes in sexual behaviour among HIV-infected women after initiation of HAART. Am J Public Health. 2004;94:1141-6.

23. Luchters S, Sarna A, Geibel S, Chersich MF, Munyao P, Kaai S, Mandaliya KN, Shikely KS, Rutenberg N, Temmerman M. Safer sexual behaviours after 12 months of antiretroviral treatment in Mombasa, Kenya: a prospective cohort. AIDS Patient Care STDS. 2008;22:587-94.

24. Crepaz N, Hart TA, Marks G. Highly active antiretroviral therapy and sexual risk behaviour: a meta-analytic review. JAMA. 2004;292:224-36.

25. Bateganya M, Colfax G, Shafer LA, Kityo C, Mugyenyi P, Serwadda D, Mayanja H, Bangsberg D. Antiretroviral therapy and sexual behaviour: a comparative study between antiretroviral naive and experienced patients at an urban HIV/AIDS care and research center in Kampala, Uganda. AIDS Patient Care STDS. 2005;19:760-8.

26. Bunnell R, Ekwaru JP, Solberg P, Wamai N, Bikaako-Kajura W, Were W, Coutinho A, Liechty C, Madraa E, Rutherford G, Mermin J. Changes in sexual behaviour and risk of HIV transmission after antiretroviral therapy and prevention interventions in rural Uganda. AIDS. 2006;20:85-92.

27. Stephenson JM, Imrie J, Davis MMD, Mercer C, Black S, Copas AJ, Hart GJ, Davidson OR, Williams IG. Is use of antiretroviral therapy among homosexual men associated with increased risk of transmission of HIV infection? Sex Transm Infect. 2003;79:7-10.

28. Diamond C, Richardson JL, Milam J, Stoyanoff S, McCutchan JA, Kemper C, Larsen RA, Hollander H, Weismuller P, Bolan R. Use of and adherence to antiretroviral therapy is associated with decreased sexual risk behaviour in HIV clinic attendees. J Acquir Immune Defic Syndr. 2005;39:211-8.

29. Eisele T, Mathews C, Chopra M, Lurie M, Brown L, Dewing S, Kendall C. Changes in risk behaviour among hiv-positive patients during their first year of antiretroviral therapy in Cape Town South Africa. AIDS Behav. 2009;13:1097-105.

30. Sarna A, Luchters S, Kaai S, Munyao P, Geibel S, Shikely K. Does being treated with HAART affect the sexual risk behavior of people living with HIV/AIDS? Insights from Mombasa, Kenya. Horizons research update. Nairobi: Population Council; 2005.

31. Frentz D, Boucher CA, van de Vijver DA. Temporal changes in the epidemiology of transmission of drug-resistant HIV-1 across the world. AIDS Rev. 2012;14:17-27.

32. World Health Organization (WHO). WHO HIV drug resistance report. Geneva: World Health Organization; 2012. p. 2012.

33. Gupta RK, Jordan MR, Sultan BJ, Hill A, Davis DH, Gregson J, Sawyer AW, Hamers RL, Ndembi N, Pillay D, Bertagnolio S. Global trends in antiretroviral resistance in treatment-naive individuals with HIV after rollout of antiretroviral treatment in resource-limited settings: a global collaborative study and meta-regression analysis. Lancet. 2012;380:1250-8.

34. Smith DM, Richman DD, Little SJ. HIV superinfection. J Infect Dis. 2005;192:438-44
35. Redd AD, Quinn TC, Tobian AA. Frequency and implications of HIV superinfection. Lancet Infect Dis. 2013;13:622-8.

36. Government of Nepal Ministry of Health and Population, National Centre for AIDS and STD Control (NCASC). Country progress report Nepal. Teku, Kathmandu: National Centre for AIDS and STD Control (NCASC); 2015. ncasc.gov.np/uploaded/publication/Reports/garpr-country-progressreport-nepal-2014-final_16jun2015.pdf.

37. Government of Nepal Ministry of Health and Population, National Centre for AIDS and STD Control (NCASC). National consolidated guidelines for treating and preventing HIV in Nepal. Teku, Kathmandu: National Centre for AIDS and STD Control (NCASC); 2014.

38. National Centre for AIDS and STD Control (NCASC). National estimates of HIV infections in Nepal. Teku, Kathmandu: National Centre for AIDS and STD Control (NCASC); 2012.

39. Auvert B, Males S, Puren A, Taljaard D, Carael M, Williams B. Can highly active antiretroviral therapy reduce the spread of HIV?: a study in a township of South Africa. J Acquir Immune Defic Syndr. 2004;36:613-21.

40. Gray RH, Li X, Wawer MJ, Gange SJ, Serwadda D, Sewankambo NK, Moore R, Wabwire-Mangen F, Lutalo T, Quinn TC. Stochastic simulation of the impact of antiretroviral therapy and HIV vaccines on HIV transmission; Rakai, Uganda. AIDS. 2003;17:1941-51.

41. Velasco-Hernandez JX, Gershengorn HB, Blower SM. Could widespread use of combination antiretroviral therapy eradicate HIV epidemics? Lancet Infect Dis. 2002;2:487-93.

42. Family Health International Nepal. Integrated biological and behavioral surveillance survey (IBBS) among female sex workers in 22 Terai highway districts of Nepal. Baluwatar: Family Health International Nepal; 2009.

43. Nepal Rastra Bank. Foreign Exchange Rates. http://www.nrb.org.np/ fxmexchangerate.php.

44. Lertpiriyasuwat C, Pradipasen M, Thiangtham W, Kaewduangjai P. Sexual behaviours during antiretroviral therapy among HIV-infected patients, Thailand. Southeast Asian J Trop Med Public Health. 2007;38:455-65.

45. Chakrapani V, Newman PA, Shunmugam M, Dubrow R. Prevalence and contexts of inconsistent condom use among heterosexual men and women living with HIV in India: implications for prevention. AIDS Patient Care STDS. 2010;24:49-58.

46. Musinguzi G, Bwayo D, Kiwanuka N, Coutinho S, Mukose A, Kabanda J, Sekabembe L, Nuwaha F. Sexual behavior among persons living with HIV in Uganda: implications for policy and practice. PLoS One. 2014;9:e85646.

47. Ung M, Boateng GO, Armah FA, Amoyaw JA, Luginaah I, Kuuire V. Negotiation for safer sex among married women in cambodia: the role of women's autonomy. J Biosoc Sci. 2013;46(1):90-106.

48. Ehrenstein V, Horton NJ, Samet JH. Inconsistent condom use among HIV-infected patients with alcohol problems. Drug Alcohol Depend. 2004;73:159-66

49. He H, Wang M, Zhang HB, Song DD, She M, Dong ZX, Qu YH, Sui X. The unprotected sexual behaviors and its influencing factors among HIVinfected men who have sex with men in Shanghai, China. Zhonghua Yu Fang Yi Xue Za Zhi. 2012;46:976-81.

50. Rees V, Saitz R, Horton NJ, Samet J. Association of alcohol consumption with HIV sex- and drug-risk behaviors among drug users. J Subst Abuse Treat. 2001;21:129-34.

51. Singh SK, Schensul JJ, Gupta K, Maharana B, Kremelberg D, Berg M. Determinants of alcohol use, risky sexual behavior and sexual health problems among men in low income communities of Mumbai, India. AIDS Behav. 2010;14(Suppl 1):S48-60.

52. Theall KP, Clark RA, Powell A, Smith H, Kissinger P. Alcohol consumption, ART usage and high-risk sex among women infected with HIV. AIDS Behav. 2007;11:205-15.

53. Leigh BC. Alcohol and condom use: a meta-analysis of event-level studies. Sex Transm Dis. 2002;29:476-82.

54. Bennett L, Dahal DR, Govindasamy P. Caste, ethnic and regional identity in Nepal: further analysis of the 2006 Nepal demographic and health survey. Calverton: Macro International Inc.; 2008. 